\title{
Evidence that Blueberry Floral Extracts Influence Secondary Conidiation and Appressorial Formation of Colletotrichum fioriniae
}

\author{
Timothy J. Waller, Jennifer Vaiciunas, Christine Constantelos, and Peter V. Oudemans ${ }^{\dagger}$
}

Rutgers University, P. E. Marucci Center for Blueberry and Cranberry Research and Extension, Chatsworth, NJ. Accepted for publication 18 December 2017.

\begin{abstract}
Blueberry anthracnose, caused by Colletotrichum fioriniae, is a preand postharvest disease of cultivated highbush blueberry (Vaccinium corymbosum). During disease development, the pathogen undergoes several lifestyle changes during host colonization, including epiphytic, quiescent, and necrotrophic phases. It is not clear, however, what if any host signals alter the pattern of colonization during the initial epiphytic phase and infection. This research investigated the role of blueberry floral extracts (FE) on fungal development. Results show that FE significantly increased both the quantity and rate of secondary conidiation and appressorial formation in vitro, suggesting that floral components could decrease the minimum time required for infection. Activity of FE was readily detected in water collected from field samples, where secondary

conidiation and appressorial formation decreased as rainwater collections were further removed from flowers. A comparison of FE from four blueberry cultivars with different levels of field susceptibility revealed that appressorial formation but not secondary conidiation significantly increased with the FE from susceptible cultivars versus resistant cultivars. Inoculum supplemented with FE produced higher levels of disease on ripe blueberry fruit as compared with inoculum with water only. Flowers from other ericaceous species were found to also induce secondary conidiation and appressorial formation of $C$. fioriniae. This research provides strong evidence that flowers can contribute substantially to the infection process of $C$. fioriniae, signifying the importance of the bloom period for developing effective disease management strategies.
\end{abstract}

Highbush blueberry (Vaccinium corymbosum L.) is an important specialty crop in the United States, with more than 89,000 acres grown nationwide and producing upward of 560 million pounds of fresh or processed fruit with a value of over $\$ 811$ million annually, according to the 2015 United States Department of Agriculture Noncitrus Fruits and Nuts Summary (USDA 2016). Blueberry anthracnose, caused by the plant pathogen Colletotrichum fioriniae (Damm et al. 2012; Oudemans et al. in press; Pszczółkowska and Okorski 2016), can cause significant preharvest and postharvest crop losses and is a primary target for disease management in many growing regions.

C. fioriniae was recently delineated from the C. acutatum species complex (Damm et al. 2012; Marcelino et al. 2008; Pennycook 2017; Shivas and Tan 2009; Sreenivasaprasad and Talhinhas 2005) that affects many valuable horticultural species (Adaskaveg and Hartin 1997; Diéguez-Uribeondo et al. 2004; Eastburn and Gubler 1990; Freeman et al. 2001; Jones et al. 1996; Lewis Ivey et al. 2004; MacKenzie et al. 2010; Moral et al. 2009; Oudemans et al. 1998; Polashock et al. 2009; Rodriguez-Salamanca et al. 2012; Smith and Black 1990; Wharton and Diéguez-Uribeondo 2004). In the original description of C. acutatum var. fioriniae (teleomorph: Glomerella acutata var. fioriniae var. nov.), isolates collected from scale insects (Fiorinia externa) shared $100 \%$ sequence similarity with isolates collected from New Jersey blueberry fruit in the D1/D2 region of the 28 S ribosomal DNA (28S), partial $\beta$-tubulin (TUB2), and matingtype gene MAT1-2 (Marcelino et al. 2008). Isolates now reclassified as $C$. fioriniae are important pathogens of almond, apple, avocado, mango, nectarine, peach, and strawberry, in addition to several Vaccinium spp., including highbush blueberry (Freeman and Shabi 1996; Guerber et al. 2003; Kou et al. 2014; Polashock et al. 2009).

†Corresponding author: P. V. Oudemans; E-mail: oudemans@rutgers.edu

Funding: We thank the William S. Haines, Sr. Endowed Cranberry Research Fund and the New Jersey Blueberry and Cranberry Research Council, Inc. for support.

(C) 2018 The American Phytopathological Society
C. fioriniae has a latent, hemibiotrophic lifestyle with a variable time lag between infection and symptom development depending on timing of infection and ripeness of the fruit (Milholland 1995; Peres et al. 2005; Prusky et al. 2013; Wharton and DiéguezUribeondo 2004; Wharton and Schilder 2008). The pathogen is known to also infect tissues other than berries, causing symptoms such as tip dieback and blossom blight, in addition to symptomless infections on leaves, inflorescence buds, and stems (Milholland 1995; Yoshida et al. 2007). On blueberry, the pathogen overwinters in blighted tissues such as dead twig tips and previous seasons' fruit pedicels (Milholland 1995; Stretch 1967) as well as dormant inflorescence buds (DeMarsay 2005; Wharton and DiéguezUribeondo 2004). Inflorescence buds have also been implicated as inoculum reservoirs in other horticultural species, including apple (Bernardi et al. 1983), sweet cherry, and sour cherry (Børve and Stensvand 2006), suggesting a close relationship of primary inoculum with floral tissues. Most Colletotrichum spp., including C. fioriniae, are well adapted to rain-splash dispersal, with conidia arising from infected tissues and spread in water droplets throughout the canopy during rain events (Boudreau and Madden 1995; Madden et al. 1996; Milholland 1995). Rain-splash-dispersed conidia may either germinate to form an appressorium that can lead to infection or increase inoculum via secondary conidiation on the surface of plant tissues (Leandro et al. 2001; MacKenzie et al. 2010; Zulfiqar et al. 1996).

Typical fungicide applications on blueberry and other hosts are aimed at preventing $C$. fioriniae from sporulating, germinating, and infecting host tissues (Boudreau and Madden 1995; Madden et al. 1996; Miles et al. 2013; Milholland 1995; Peres et al. 2005; Wharton et al. 2002; Yang et al. 1990). For successful management of blueberry anthracnose, fungicide applications initiated during open bloom are most effective for preventing the formation of seasonlong latent infections (Milholland 1995; Verma et al. 2006). Interestingly, several studies have shown a synchronization of conidial production and the bloom period (DeMarsay 2005; Miles et al. 2013; Wharton et al. 2002); however, it is unknown whether flowers signal the initiation of conidial production and disease development. 
Because the critical disease control period begins during bloom, the biological importance of floral components on the disease cycle of C. fioriniae needs to be explored more fully.

Flowers have been implicated in at least two pathosystems involving members of the $C$. acutatum species complex (Agostini et al. 1993; Leandro et al. 2001, 2003; MacKenzie et al. 2010; Peres et al. 2005; Wharton and Diéguez-Uribeondo 2004). C. acutatum (sensu lato) can also cause floral infections on almond, citrus, mango, and strawberry that lead to significant crop losses (Adaskaveg and Hartin 1997; Jeffries et al. 1990; Maas 1984; Zulfiqar et al. 1996). This research was conducted to investigate the role of waterdispersible blueberry floral components on secondary conidiation and appressorial formation of $C$. fioriniae during the initial stages of pathogen development.

\section{MATERIALS AND METHODS}

Fungal isolates. The primary isolate of $C$. fioriniae used in this research was BB\#10, isolated in 2005 from an infected blueberry fruit at the P. E. Marucci Center for Blueberry and Cranberry Research and Extension, Rutgers University in Chatsworth, NJ (PEM). BB\#10 matched the description of $C$. fioriniae and shared $100 \%$ sequence similarity to the diagnostic regions (internal transcribed spacer), TUB2, and partial actin (Gen Bank JQ040070, JQ040075, and JQ040050, respectively) of C. fioriniae type material, CBS 128517 (Gen Bank NR_111747, JQ949943, and JQ949613, respectively). The TUB2 region (Gen BankEF593325) of the original C. acutatum var. fioriniae isolate (Marcelino et al. 2008) was compared as well and showed 99\% sequence similarity. In addition to BB\#10, four other $C$. fioriniae isolates were used in one assay. BB-89 and CB-KPCF16 were isolated from naturally infected blueberry and cranberry fruit, respectively, collected at PEM. CB-PMAP182 and CB-PMAP184 were collected from symptomatic cranberry fruit at local growers' farms in Chatsworth, NJ and Shamong, NJ, respectively. All isolates matched $C$. fioriniae conidial and morphological descriptions as well as $99 \%$ sequence similarity with the accessions previously described (Oudemans et al. in press).

Single-spore isolates were stored on cornmeal agar (Becton, Dickinson and Company, Sparks, MD). High-density sporulation was induced by streaking conidia onto clarified V8 juice agar (Miller 1955) with no calcium carbonate and a higher concentration of agar (28 g/liter). Cultures were incubated at $25^{\circ} \mathrm{C}$ in the dark for 7 days and spore suspensions were prepared by washing the conidia with sterile deionized water (SDW) from the high-density plates. Spore concentrations were estimated using a hemocytometer and adjusted to either $1.0 \times 10^{5}$ or $5.0 \times 10^{5} \mathrm{conidia} / \mathrm{ml}$ of SDW, depending on the assay.

Preparation of floral extracts. Blueberry flowers (V. corymbosum L.) were collected from two fungicide-free blueberry plantings at PEM during peak bloom over three growing seasons, from 2013 to 2016. Flowers were processed using a protocol modified from Leandro et al. (2003). Prior to destructive extraction, the ovaries, sepals, and peduncles were discarded and the remaining corolla, stigma, style, and stamen were then divided into $10-\mathrm{g}$ samples and stored up to 3 days at $4{ }^{\circ} \mathrm{C}$ until processed. Floral extracts (FE) were prepared by grinding 10-g samples with a mortar and pestle in $90 \mathrm{ml}$ of SDW (a 1:9 weight/volume ratio) for $30 \mathrm{~s}$ (care was taken to not pulverize the samples). The resulting pulp sample was strained through four layers of sterile cheesecloth and further clarified by centrifugation for 10 min at $8,055 \times g$. The supernatant was vacuum filtered through Whatman number 1 filter paper (Maidenstone, UK) and filter sterilized (CAMEO 25 GAS, $0.22 \mu \mathrm{m}$; Osmonics Penang, Malaysia). Extracts were stored at $-20^{\circ} \mathrm{C}$ in $15-\mathrm{ml}$ aliquots until experimental use. Blueberry FE prepared using this method included anthracnosesusceptible V. corymbosum L. 'Bluecrop' and 'Coville', moderately resistant 'Duke', and resistant 'Elliot'. Flowers of four ericaceous species were also collected in the forest surrounding PEM as well as a greenhouse-grown, sterile triploid mutant of $V$. vitis-idaea L. collected from the pathology research greenhouse at PEM. Flowers from various ericaceous species were collected during the peak bloom period (early spring through early summer) for each species examined and FE was made using methods and floral tissues described. A passive extraction was utilized in one assay. Bluecrop flowers $(50 \mathrm{~g}$ of whole flowers with only peduncles removed) were placed into plastic mesh containers and sprayed with $250 \mathrm{ml}$ of SDW using a standard laboratory spray-mist bottle and the collected runoff, referred to as Bluecrop passive FE, was divided into $15-\mathrm{ml}$ aliquots and frozen at $-20^{\circ} \mathrm{C}$ until use.

Bioactivity of FE. A protocol modified from Leandro et al. (2003) was utilized to estimate biological activity of numerous FE. C. fioriniae isolates, described above, were assayed for growth responses (secondary conidiation and appressorial formation) in the presence or absence of blueberry FE. Assays were conducted in $40-\mu \mathrm{l}$ droplets placed on 22-by-22-mm glass coverslips (triple rinsed with $95 \% \mathrm{EtOH}$ and dried prior to use). Each $40-\mu$ d droplet contained equal volumes of conidial suspension $\left(1.0 \times 10^{5}\right.$ for all assays except the 24 -h time course, where the concentration was $5.0 \times 10^{5}$ conidia $/ \mathrm{ml}$ of SDW), SDW, and FE, aliquoted from a previously combined solution (500- $\mu$ l portions). Bluecrop FE (BC FE) was used in this assay and, for untreated controls, SDW replaced FE so that conidial concentrations were consistent. Glass coverslips with droplets were incubated in plastic cell culture dishes at high humidity at $25^{\circ} \mathrm{C}$ in the dark. Growth responses in the droplets were evaluated at 0 and $24 \mathrm{~h}$ by first adding $15 \mu \mathrm{l}$ of lactophenol cotton-blue $(20.0 \mathrm{~g}$ of phenol crystals, $20.0 \mathrm{ml}$ of $2.5 \%$ lactic acid, $40.0 \mathrm{ml}$ of glycerol, and $0.05 \mathrm{~g}$ of cotton blue) to the droplet and then carefully inverting coverslips and placing them droplet side down on a glass microscope slide to facilitate microscopic examination. Observations were made across 16 microscope fields at $\times 400$ magnification, totaling an area of $3.808 \mathrm{~mm}^{2}$. Two treatments were replicated three times in a completely randomized design and the experiment was conducted twice. A 24-h time-course assay was also conducted as previously described using one $C$. fioriniae isolate, BB\#10, with evaluations every $2 \mathrm{~h}$ over a 24 -h period and consisted of three replicates per time point per treatment in a completely randomized design. The experiment was conducted twice. In order to determine whether any cultivar effects were present, two susceptible cultivars (Coville and Bluecrop) and two resistant cultivars (Duke and Elliot) were selected (Polashock et al. 2005) and the bioactivity of the FE on $C$. fioriniae (BB\#10) were compared among cultivars following the methods described above. Evaluation of appressorial formation was made at $24 \mathrm{~h}$ postinoculation and the experiment consisted of three replicates per treatment in a completely randomized design. The experiment was conducted three times. In another experiment, the FE of four ericaceous species were evaluated for bioactivity on C. fioriniae (BB\#10) following methods described above. Treatments included the FE of the four ericaceous species, an SDW control, and BC FE as a positive control. Evaluation of growth responses were made at $24 \mathrm{~h}$ postinoculation and the experiment consisted of three replicates per treatment in a completely randomized design. The experiment was conducted twice.

Blueberry fruit inoculation. An inoculation trial was conducted to determine whether FE from Bluecrop (susceptible) and Elliot (resistant) increased the occurrence of infection on fruit. Visually healthy Elliot fruit were collected from a field at PEM that received no fungicides. This cultivar was utilized as substrate due to its low frequency of anthracnose compared with Bluecrop, where high background levels of $C$. fioriniae are persistent. Plastic sealable containers (305 by 127 by $76 \mathrm{~mm}$ ), lined with sterile, moistened paper towels and sterile plastic netting placed above towels, were used as inoculation chambers. Forty fruit placed into each container represented a single replicate. In total, five replicates were used for each of the six treatments: Elliot fruit treated with FE alone (either Bluecrop or Elliot), Bluecrop or Elliot FE plus conidia (BB\#10), conidia alone, and an SDW-only control. Containers were organized as a randomized complete block design and each were 
treated individually by misting approximately $1 \mathrm{ml}$ of inoculum over the fruit using a standard laboratory pump sprayer (30-ml capacity). Containers were then sealed to promote a high relative humidity and held at room temperature (approximately $22^{\circ} \mathrm{C}$ ) with 12 -h photoperiods. Fruit were evaluated for disease development 1 week postinoculation and the entire experiment was conducted twice.

Comparison of destructive and passive $\mathrm{BC}$ FE, and rainwater runoff collection of FE. Destructive (mortar and pestle) FE and passive (SDW spray) FE were compared for bioactivity on C. fioriniae (BB\#10) following methods described. Evaluation of growth responses (secondary conidiation and appressorial formation) were made at $24 \mathrm{~h}$ postinoculation and the experiment consisted of three replicates per treatment in a completely randomized design. The experiment was conducted twice. Rainwater was collected from three Bluecrop bushes by placing a funnel connected to a 50-ml centrifuge tube either directly beneath an inflorescence (denoted as flower), halfway between top of the plant and crown (stem), and at the base of the bush (crown), as well as rainwater that had not contacted the bush (ground). The assay was performed using the same methods as previously described, with evaluations at $24 \mathrm{~h}$ postinoculation using $C$. fioriniae isolate BB\#10. The experiment consisted of three replicates per treatment in a completely randomized design. The experiment was conducted twice.

Sporulation on developing inflorescence buds. In total, 100 Bluecrop stems, each containing at least five inflorescence buds, were collected in November following leaf drop. Five nonsurface-sterilized Bluecrop stems were placed in plastic sealable containers ( 305 by 127 by $76 \mathrm{~mm}$ ) lined with sterilized wetted paper towels and sterile plastic netting. Containers were inoculated individually by misting approximately $1 \mathrm{ml}$ of either BC FE/SDW (1:1) or SDW alone over the fruit using a standard laboratory pump sprayer (30-ml capacity). Containers were then sealed to promote a high relative humidity and held at room temperature (approximately $22^{\circ} \mathrm{C}$ ) with 12 -h photoperiods. Data were collected on the first five inflorescence buds from the apical end of each stem per treatment per block. Inflorescence buds were visually assessed for active sporulation at 2, 3, and 4 weeks postinoculation. The experiment consisted of three replicates per treatment, and the assay was conducted twice.

Data analyses. All analyses were conducted using CoStat (version 4.0; CoHort Software, Monterey, CA) (Cardinali and Nason 2013). For the coverslip bioactivity experiments, data from 16 microscope fields were summed for each replicate. Data were checked for normality using Bartlett's test for homogeneity of variances and, if necessary, normalized using a $\log _{10}$ transformation with a constant of 0.5 added to compensate for 0 count data. All experiments were conducted at least twice and a completely randomized two-way analysis of variance (ANOVA) was applied using experiment and treatment as independent variables and either total conidia or appressoria as the dependent variable. The results were expressed as the back-transformed means per square millimeter of total conidia (comprised of primary and secondary conidia) or appressoria per square millimeter. In cases where a significant interaction between experiment and treatment occurred, the experiments were analyzed independently using a completely randomized 1-way ANOVA. Fruit inoculation and sporulation on developing inflorescence buds were analyzed using a randomized complete block 1-way ANOVA. The results were reported as percent infected fruit and percent sporulating buds, respectively. A post hoc Fisher's least significant difference (LSD) test was performed for means separation.

\section{RESULTS}

BC FE stimulates an increased rate and magnitude of secondary conidiation and appressorial formation of $C$. fioriniae. Two assays were implemented: first, to determine the effects of $\mathrm{BC}$ FE on multiple $C$. fioriniae isolates; and, second, a detailed 24-h time course to estimate a growth response timeline. The SDW control (Fig. 1A) was compared with BC FE (Fig. 1B), where BC FE had pronounced effects on secondary conidiation and appressorial formation of all $C$. fioriniae isolates at $24 \mathrm{~h}$ (Table 1). The FE was found to have three visible effects on $C$. fioriniae: (i) increased secondary conidiation similar to that reported previously (Leandro et al. 2001, 2003) (Fig. 1C), (ii) increased appressorial formation (Fig. 1D), and (iii) increased hyphal density although not quantified in this study (Fig. 1E). In a detailed time-course experiment, the rate of secondary conidiation and appressorial formation was compared with or without BC FE over $24 \mathrm{~h}$ using isolate BB\#10. Secondary conidiation began after $6 \mathrm{~h}$ in the presence of $\mathrm{FE}$ and was significantly greater $(P=0.0391)$ than SDW treatments (Fig. 2A). Appressorial formation was also significantly greater in the presence of BC FE after $6 \mathrm{~h}(P \leq 0.0001)$ (Fig. 2B). Conidia visibly produced more germ tubes, leading to an overall greater hyphal density in the presence of FE as compared with conidia in SDW, where conidia typically produced a single germ tube, infrequently producing appressoria sessile to conidia. In many cases, conidia in the presence of FE formed appressoria at early time points, which

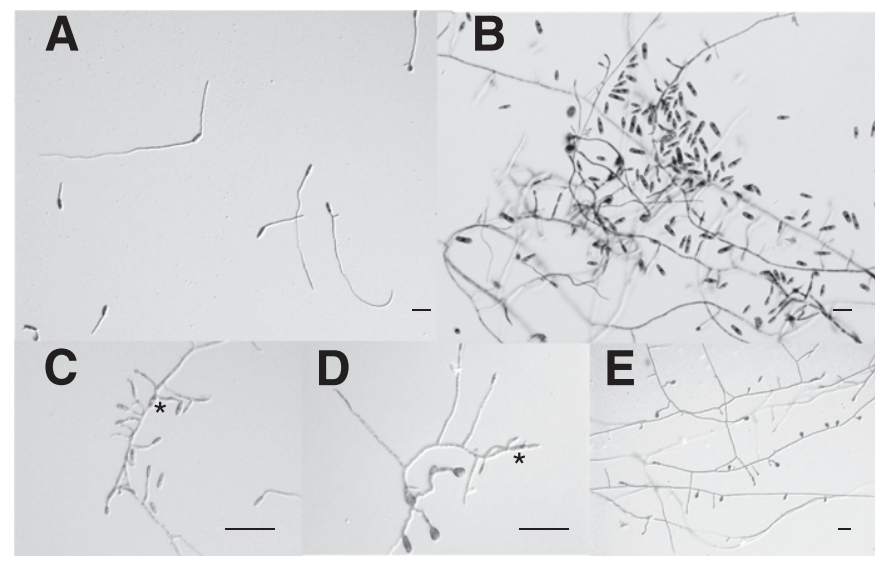

Fig. 1. Appressorial formation and secondary conidiation of Colletotrichum fioriniae on glass coverslips with and without floral extracts. A, Primary conidia in sterile deionized water (SDW) at $24 \mathrm{~h}$ postinoculation. B, Primary and secondary conidia, with appressoria in the presence of Bluecrop floral extract (BC FE) at $24 \mathrm{~h}$ postinoculation. C, Primary conidium (*) germinating and in the process of forming secondary conidia in the presence of BC FE on a glass coverslip at $24 \mathrm{~h}$ postinoculation. D, Primary conidium (*) germinating and in the process of appressorial formation in the presence of BC FE on a glass coverslip at $24 \mathrm{~h}$ postinoculation. E, Mycelial growth and abundant appressorial formation in the presence of rainwater collected from under a Bluecrop inflorescence in the field. Scale bars: $40 \mu \mathrm{m}$.

TABLE 1. Comparison of secondary conidiation and appressorial formation with and without Bluecrop floral extract (BC FE) using five Colletotrichum fioriniae isolates ${ }^{\mathrm{z}}$

\begin{tabular}{llcrr}
\hline Isolate & Treatment & 0 h Conidia & 24 h Conidia & 24 h APP \\
\hline BB\#10 & BC FE & $2.9 \mathrm{a}$ & $37.0 \mathrm{a}$ & $10.7 \mathrm{a}$ \\
& SDW & $2.7 \mathrm{a}$ & $4.7 \mathrm{~b}$ & $0.5 \mathrm{~b}$ \\
BB-89 & BC FE & $2.9 \mathrm{a}$ & $56.1 \mathrm{a}$ & $24.2 \mathrm{a}$ \\
& SDW & $2.7 \mathrm{a}$ & $5.4 \mathrm{~b}$ & $0.9 \mathrm{~b}$ \\
CB-PMAP182 & BC FE & $3.1 \mathrm{a}$ & $70.3 \mathrm{a}$ & $23.2 \mathrm{a}$ \\
& SDW & $2.6 \mathrm{a}$ & $9.9 \mathrm{~b}$ & $0.6 \mathrm{~b}$ \\
CB-PMAP184 & BC FE & $2.8 \mathrm{a}$ & $42.1 \mathrm{a}$ & $20.6 \mathrm{a}$ \\
& SDW & $2.7 \mathrm{a}$ & $4.6 \mathrm{~b}$ & $0.4 \mathrm{~b}$ \\
CB-KPCF16 & BC FE & $2.5 \mathrm{a}$ & $45.7 \mathrm{a}$ & $31.0 \mathrm{a}$ \\
& SDW & $2.6 \mathrm{a}$ & $4.9 \mathrm{~b}$ & $0.4 \mathrm{~b}$ \\
\hline
\end{tabular}

$\mathrm{z}$ Analysis performed on $\log _{10}$-transformed means of total conidia (denoted as Conidia, comprising primary and secondary conidia) and appressoria coverslip count data at 0 and $24 \mathrm{~h}$ per isolate. Values are presented as back-transformed means per square millimeter, and the experiment was conducted twice. Letters indicate significant differences between treatments per isolate at $P<0.05$ according to Fischer's least significant difference test. Abbreviations: SDW = sterile deionized water and APP $=$ appressoria. 
germinated to form additional appressoria. FE-treated conidia would ultimately form aggregates, resulting in appressoria stacked upon each other by $24 \mathrm{~h}$ postinoculation.

FE of susceptible cultivars stimulated the greatest C. fioriniae appressorial response in vitro. Given that there is a known range of susceptibility in blueberry to anthracnose, a test was conducted to determine whether FE of susceptible and resistant cultivars affected $C$. fioriniae appressorial formation differently. FE from susceptible Coville and Bluecrop induced significantly more appressoria than those of moderately resistant Duke, resistant Elliot, and the SDW control at $24 \mathrm{~h}$ postinoculation (Table 2). Observations clearly demonstrated active secondary conidiation of C. fioriniae in the presence of all blueberry FE evaluated. Results for each experiment are presented separately due to a significant interaction between experiment and treatment. Results from the three replicated trials all show significantly greater appressorial formation for the susceptible cultivars FE as compared with the resistant and moderately resistant cultivars and SDW control in vitro.

Blueberry FE enhances $C$. fioriniae infectivity on Elliot fruit. Prior assays demonstrated an increase in $C$. fioriniae
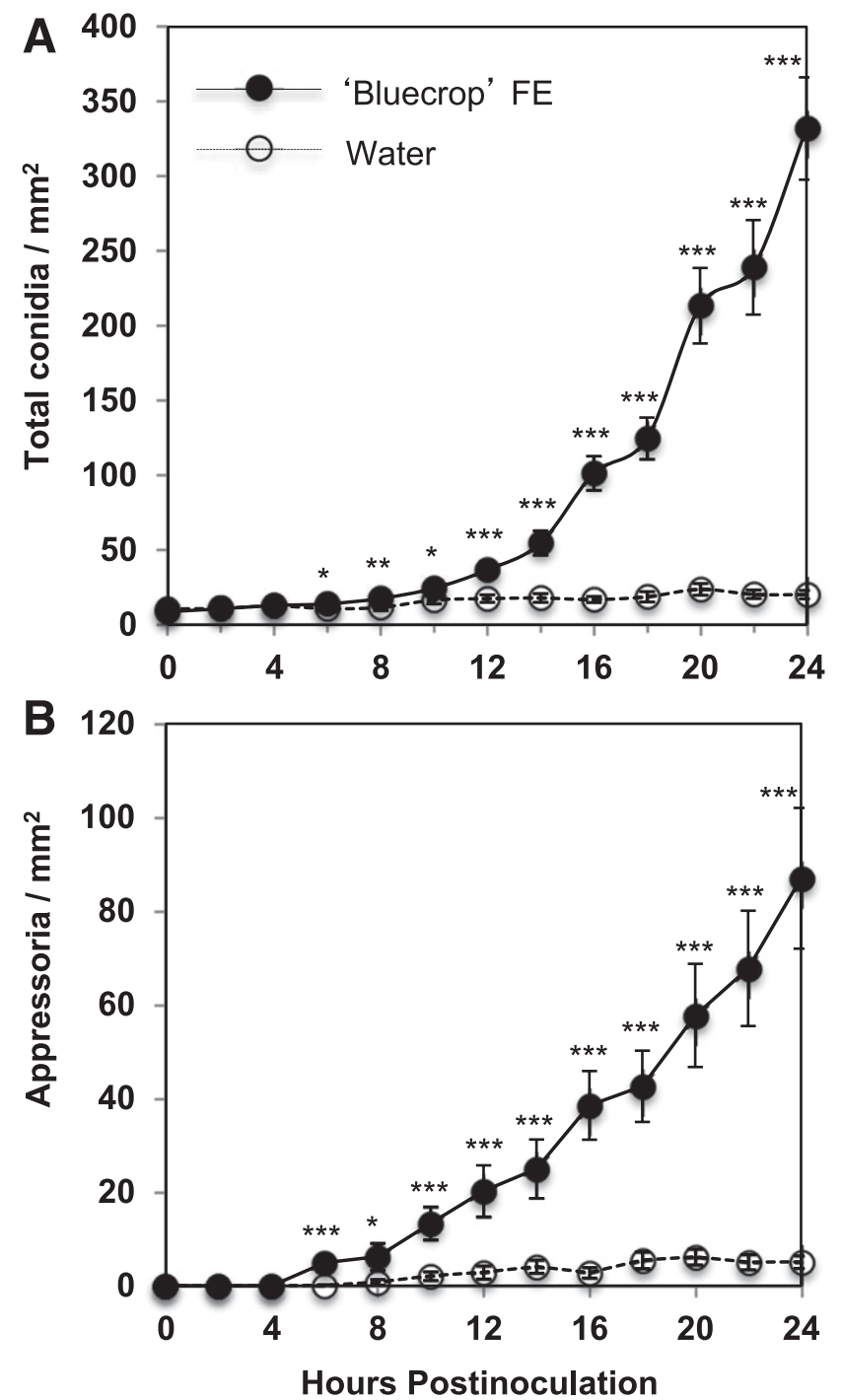

Fig. 2. Time-course study of secondary conidiation and appressorial formation of Colletotrichum fioriniae (isolate BB\#10) in the presence (O) or absence (O) of Bluecrop floral extract (BC FE). A, Secondary conidiation was evaluated as total conidia (primary conidia at $0 \mathrm{~h}$ were 9.0 and 10.8 conidia $/ \mathrm{mm}^{2}$ for $\mathrm{BC} \mathrm{FE}$ and water, respectively; $P=0.773$ ). B, Appressorial formation. Asterisks *, **, and $* * *$ indicate level of significance of $P<0.05,0.01$, and 0.005 , respectively. Error bars indicate standard deviation of count data. appressorial formation in the presence of some FE, leading us to question whether FE could enhance $C$. fioriniae infection on sound, fungicide-free, Elliot blueberry fruit. C. fioriniae (BB\#10) conidia in the presence of either susceptible Bluecrop or resistant Elliot FE induced significantly higher levels of disease as compared with treatments lacking FE (Table 3). FE without conidia and conidia without FE produced similar levels of disease according to an LSD test with an $\alpha$ of 0.05 . Data were collected at 1 week postinoculation and were analyzed separately due to interaction effects between experiment and treatment; however, both trials followed the same general trend of increased infection with conidia in the presence of FE.

Bioactive stimulants can be captured through passive extraction and blueberry flower rainwater runoff. Two extraction types, destructive and passive, were compared to determine whether or not FE could be moved passively into water without the need for tissue maceration. Bluecrop passive FE, prepared by mimicking a wetting event such as rainfall, stimulated greater secondary conidiation than the SDW control, although not to the same extent observed with destructive BC FE obtained with mortar and pestle (Fig. 3A). This same trend was also observed for appressorial formation, where destructive BC FE stimulated 42.2 appressoria/ $\mathrm{mm}^{2}$, followed by Bluecrop passive FE (15.4 appressoria/ $\mathrm{mm}^{2}$ ) and SDW control (5.1 appressoria/ $\mathrm{mm}^{2}$ ), demonstrating the movement of stimulatory compounds by nondestructive means. Rainwater collected from Bluecrop bushes directly beneath inflorescence (flower), halfway between inflorescence and crown (stem), base of bush (crown), and virgin rainwater collected away from the bush (ground) were compared with SDW and showed different levels of stimulatory effects on conidia (Fig. 3B). Secondary conidial production and appressorial formation decreased as rainwater collections were further removed from flowers. Comparing the rainwater (ground) and SDW treatments, there was no

TABLE 2. Comparison of floral extracts from susceptible and resistant blueberry cultivars on appressorial formation of Colletotrichum fioriniae ${ }^{x}$

\begin{tabular}{lcrrr}
\hline & & \multicolumn{3}{c}{ Appressoria/mm $\mathrm{mm}^{2 \mathrm{y}}$} \\
\cline { 3 - 5 } Cultivar & Susceptibility $^{\mathrm{z}}$ & Trial 1 & Trial 2 & Trial 3 \\
\hline Coville & $\mathrm{S}$ & $11.9 \mathrm{~b}$ & $20.4 \mathrm{a}$ & $11.5 \mathrm{a}$ \\
Bluecrop & $\mathrm{S}$ & $20.8 \mathrm{a}$ & $11.8 \mathrm{~b}$ & $11.1 \mathrm{a}$ \\
Duke & $\mathrm{MR}$ & $6.5 \mathrm{c}$ & $3.4 \mathrm{c}$ & $2.1 \mathrm{~b}$ \\
Elliot & $\mathrm{R}$ & $4.8 \mathrm{c}$ & $3.9 \mathrm{c}$ & $0.3 \mathrm{c}$ \\
SDW & $\ldots$ & $1.7 \mathrm{~d}$ & $0.3 \mathrm{~d}$ & $0 \mathrm{c}$
\end{tabular}

x C. fioriniae isolate BB\#10 was used in this experiment.

y Analysis performed on $\log _{10}$-transformed means of appressoria coverslip count data at $24 \mathrm{~h}$; values are presented as back-transformed means per square millimeter. Letters indicate significant differences at $P<0.05$ according to Fischer's least significant difference test.

z Blueberry cultivar anthracnose susceptibility ranking based on fruit inoculations by Polashock et al. (2005). Abbreviations: $\mathrm{S}=$ susceptible, $\mathrm{MR}=$ moderately resistant, and $\mathrm{R}=$ resistant.

TABLE 3. Impact of floral extracts (FE) on percent infection of Elliot blueberry fruit by Colletotrichum fioriniae ${ }^{y}$

\begin{tabular}{llll}
\hline & & \multicolumn{2}{c}{ Infection at 1 week $(\%)^{\mathrm{z}}$} \\
\cline { 3 - 4 } FE & C. fioriniae & Trial 1 & Trial 2 \\
\hline Bluecrop & No conidia & $29.5 \mathrm{~b}$ & $38.5 \mathrm{~b}$ \\
Elliot & No conidia & $35 \mathrm{~b}$ & $38.5 \mathrm{~b}$ \\
Bluecrop & Conidia & $51.5 \mathrm{a}$ & $64 \mathrm{a}$ \\
Elliot & Conidia & $45.5 \mathrm{a}$ & $69.5 \mathrm{a}$ \\
None & Conidia & $32 \mathrm{~b}$ & $42 \mathrm{~b}$ \\
None & None & $3.5 \mathrm{c}$ & $22 \mathrm{c}$ \\
\hline
\end{tabular}

y $C$. fioriniae isolate BB\#10 was used in this experiment.

$\mathrm{z}$ Analysis performed on percent infected fruit showing signs of sporulation at 1 week postinoculation. Letters indicate significant differences at $P<0.05$ according to Fischer's least significant difference test. Trial 1: block $P=$ 0.2556 . Trial 2 (later in the season): block $P=0.3373$. 
significant increase of appressorial formation and only a slight increase of secondary conidiation in the virgin rainwater.

Multiple ericaceous species FE stimulate $C$. fioriniae secondary conidiation and appressorial formation. FE from five ericaceous species, including Kalmia latifolia L. (mountain laurel, native), Lyonia mariana (L.) D. Don (staggerbush, native), Rhododendron maximum L. (rhododendron a.k.a. great laurel, native), V. macrocarpon Ation (cranberry, native) and $V$. vitis-idaea L. (lingonberry, nonnative) were compared with $V$. corymbosum L. (Bluecrop) FE for their effects on secondary conidiation and appressorial formation. FE from four of the five nonblueberry sources stimulated significantly more secondary conidiation than the SDW control. The sole exception was FE from a greenhousegrown, sterile triploid mutant of $V$. vitis-idaea L. (Table 4). FE from Bluecrop blueberry and the related species V. macrocarpon Ation (cranberry) consistently had the highest level of secondary
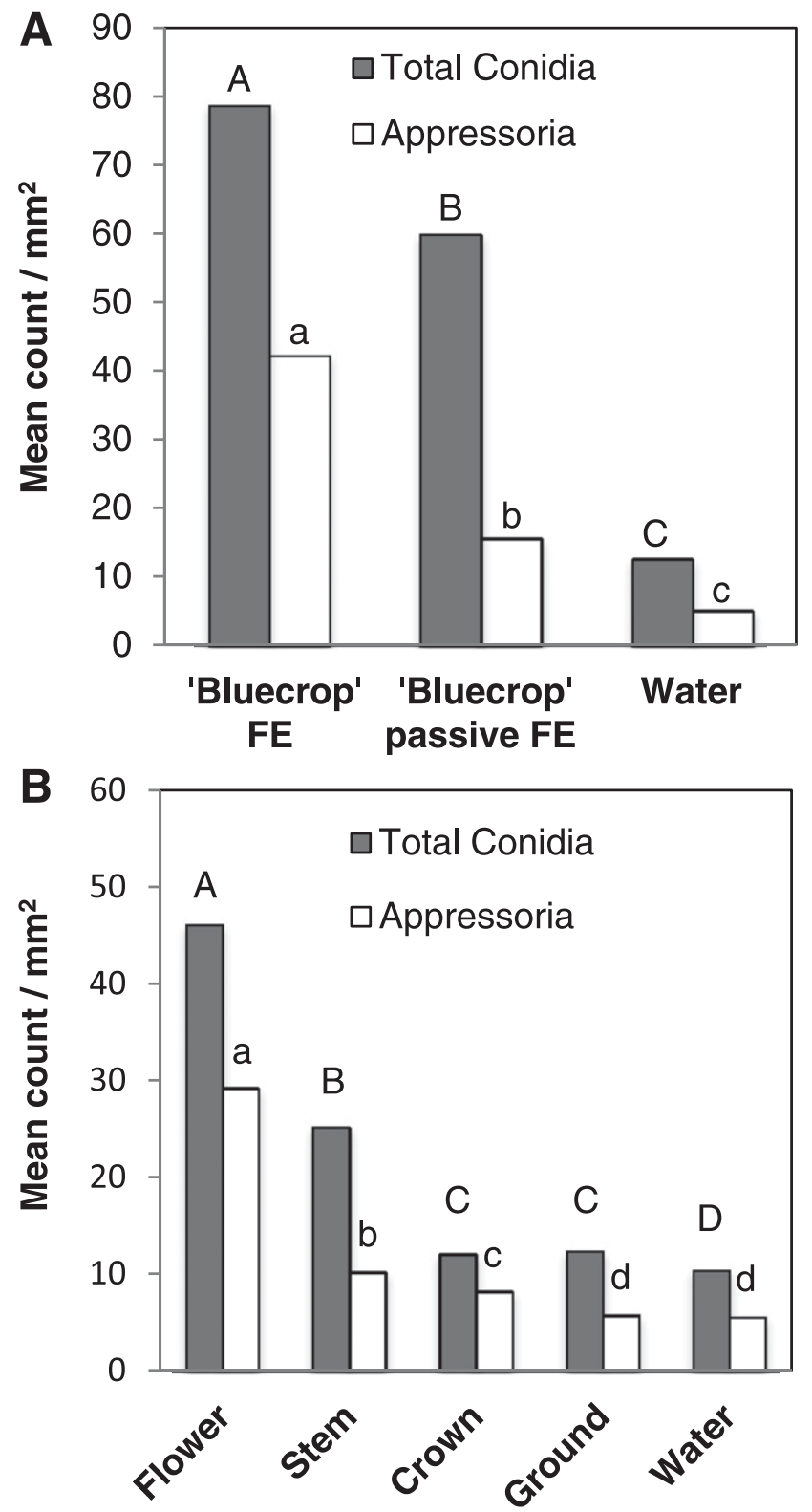

Fig. 3. Results of bioassays to detect activity of floral extracts (FE) collected from different sources on Colletotrichum fioriniae (isolate BB\#10) at $24 \mathrm{~h}$ postinoculation. Secondary conidiation and appressorial formation increased in the presence of passive FE. A, Bluecrop passive FE performed similarly to standard Bluecrop FE, although with a lower response. B, Activity of rainwater collected at increasing distances from Bluecrop inflorescences. Letters indicate significant differences at $P<0.05$ according to Fischer's least significant difference test: uppercase $=$ total conidia and lowercase $=$ appressoria. conidiation compared with extracts from the other plant species. Likewise, with the exception of $V$. vitis-idaea L., FE from the different plant species significantly increased appressorial formation when compared with the SDW control (Table 4). Data from each experiment was analyzed independently due to considerable variation in secondary conidiation between trials.

FE increases $C$. fioriniae sporulation on developing blueberry inflorescence buds. To determine whether flowers could influence sporulation of overwintered appressoria, stems with dormant inflorescence buds were treated with BC FE and were evaluated at 2,3, and 4 weeks postinoculation for active sporulation. Stems examined at 2 weeks posttreatment in the first trial showed a significant increase in sporulation in the presence of FE compared with SDW ( $P=0.016)$ but, as time further progressed, floral buds were beginning to expand and sporulation was abundant in both treatments (Table 5). In a second experiment, inflorescences had begun to emerge and sporulation was not significantly different. Results were analyzed independently due to interaction effects between experiment and treatment.

\section{DISCUSSION}

Extracts from blueberry flowers were found to affect all C. fioriniae isolates evaluated in this study similarly. The primary

TABLE 4. Comparison of floral extracts (FE) from select species in Ericaceae on secondary conidiation and appressorial formation of Colletotrichum fioriniae $^{y}$

\begin{tabular}{llcccc}
\hline & \multicolumn{2}{c}{$24 \mathrm{~h}$ Conidia } & & \multicolumn{2}{c}{$24 \mathrm{~h}$ Appressoria } \\
\cline { 2 - 3 } \cline { 6 - 7 } FE & Trial 1 & Trial 2 & & Trial 1 & Trial 2 \\
\hline Vaccinium corymbosum & $89.4 \mathrm{a}$ & $350 \mathrm{a}$ & & $11.9 \mathrm{ab}$ & $13.4 \mathrm{a}$ \\
V. macrocarpon & $72.3 \mathrm{a}$ & $174 \mathrm{~b}$ & & $4.7 \mathrm{abc}$ & $2.5 \mathrm{~b}$ \\
Kalmia latifolia & $59.7 \mathrm{a}$ & $78.1 \mathrm{~d}$ & & $15.1 \mathrm{a}$ & $8.6 \mathrm{a}$ \\
V. vitis-idaea & $42.4 \mathrm{ab}$ & $95.1 \mathrm{~cd}$ & & $4 \mathrm{bc}$ & $1.6 \mathrm{bc}$ \\
Lyonia mariana & $54.2 \mathrm{a}$ & $76.2 \mathrm{~d}$ & & $10.4 \mathrm{ab}$ & $8.9 \mathrm{a}$ \\
Rhododendron maximum & $72.9 \mathrm{a}$ & $126 \mathrm{c}$ & & $10.5 \mathrm{ab}$ & $10.6 \mathrm{a}$ \\
SDW & $13.7 \mathrm{~b}$ & $11.8 \mathrm{e}$ & & $2.9 \mathrm{c}$ & $0.6 \mathrm{c}$ \\
\hline
\end{tabular}

y C. fioriniae isolate BB\#10 was used in this experiment. Analysis was performed on $\log _{10}$-transformed means of total conidia (denoted as Conidia, comprising primary and secondary conidia) and appressoria coverslip count data at $24 \mathrm{~h}$. Values are presented as back-transformed means per square millimeter and the experiment was conducted twice. Letters indicate significant differences at $P<0.05$ according to Fischer's least significant difference test.

${ }^{\mathrm{z}}$ Flowers were collected in Chatsworth, NJ over two growing seasons (2014 and 2015). Bluecrop FE was utilized for V. corymbosum. SDW = sterile deionized water.

TABLE 5. Effect of Bluecrop floral extract (BC FE) on conidiation of native Colletotrichum fioriniae from dormant Bluecrop inflorescence buds ${ }^{z}$

\begin{tabular}{lclcc}
\hline Trial & Time $($ weeks $)$ & Treatment & Sporulation $(\%)$ & $P$ value \\
\hline 1 & 2 & BC FE & 2.8 & $0.016^{*}$ \\
& $\ldots$ & SDW & 0 & $\ldots$ \\
1 & 3 & BC FE & 9.6 & 0.120 \\
& $\ldots$ & SDW & 4.8 & $\ldots$ \\
1 & 4 & BC FE & 14.0 & 0.909 \\
& $\ldots$ & SDW & 12.8 & $\ldots$ \\
2 & 2 & BC FE & 3.2 & 0.609 \\
& $\ldots$ & SDW & 4.4 & $\ldots$ \\
2 & 3 & BC FE & 3.6 & 0.319 \\
& $\ldots$ & SDW & 4.8 & $\ldots$ \\
2 & 4 & BC FE & 3.6 & 0.609 \\
& $\ldots$ & SDW & 5.6 & $\ldots$
\end{tabular}

z Note: no conidia were added for this experiment. Analysis was performed on mean percent sporulating inflorescence buds at designated time points for both trials separately. Time indicates duration of floral extract on inflorescence buds. An asterisk indicates significance at $P<0.05$. Inflorescence buds were from nonfungicide-treated plots over two growing seasons. SDW = sterile deionized water. 
effects were increased rate and magnitude of both secondary conidiation and, unique to this study, appressorial formation. Furthermore, an increase of fruit infection was observed with $C$. fioriniae conidia in the presence of FE. Interestingly, appressorial formation was influenced by cultivar, with FE from susceptible varieties inducing more appressoria in vitro than those of resistant varieties. The activity of FE was detected in both simulated rainfall and natural rainwater collected from flowers in the field. The observations collectively provide strong evidence that FE likely affect the disease cycle of $C$. fioriniae.

Previous studies have demonstrated increased secondary conidiation of C. acutatum (sensu lato) in response to floral components in the strawberry anthracnose pathosystem (Leandro et al. 2003) as well as sporulation of persistent calyces (buttons) in citrus postbloom fruit drop (MacKenzie et al. 2010), both resulting in greater disease. In this study, blueberry FE not only increased inoculum but also had decided effects on appressorial formation.

FE affected secondary conidiation and appressorial formation differently, suggesting that their induction may be due to different floral compounds. All blueberry cultivars stimulated secondary conidiation equally, suggesting a nutritional role of the FE. MacKenzie et al. (2010) demonstrated increased propagule formation in response to $2.5 \%$ sucrose solutions, a common floral component. However, differences in host genotype were found here to influence the pattern of appressorial formation and this may be related to other components such as longchain fatty acids (Gager 2015; Podila et al. 1993). FE from susceptible Bluecrop increased the rate of appressorial formation, suggesting that some floral components strongly influence the infection period and may shorten the time needed for a successful infection to occur. Previous research concluded that a minimum of 10 to $12 \mathrm{~h}$ of continual wetness is required for blueberry fruit infections at 11 to $27^{\circ} \mathrm{C}$ (Hartung et al. 1981; Verma et al. 2007). Because these studies were conducted in the absence of floral tissues, the estimated minimum wetness period may be too conservative during the blueberry bloom period. Diéguez-Uribeondo et al. (2011) reported a dramatically shorter wetness period required to establish infection on almond blossoms ( $3 \mathrm{~h}$ at 15 to $20^{\circ} \mathrm{C}$ ) compared with almond leaves $\left(24 \mathrm{~h}\right.$ at 15 to $\left.20^{\circ} \mathrm{C}\right)$ when inoculated with C. acutatum, suggesting that floral infections occur more rapidly. In light of the results presented here, we hypothesize that floral stimulation likely reduces infection period time requirements.

The rainwater collections provide evidence that the stimulatory compounds originate from blueberry flowers and can be mobilized in rainwater. The mobility of FE in water under field conditions suggests that stimulatory effects may extend to infection courts located on the fruit pedicel, on fertilized ovaries where petals have already dropped as well as other susceptible tissues. This is similar to floral compounds being "washed" or mobilized from citrus flowers, over some distance, onto the persistent calyces and stimulating the production of conidia (MacKenzie et al. 2010). Thus, FE carried in rainwater could affect multiple inoculum reservoirs and synchronize C. fioriniae sporulation on dead twig tips as well as on developing blueberry inflorescences (DeMarsay 2005; Miles et al. 2013; Milholland 1995; Wharton et al. 2002).

Resistance to anthracnose in highbush blueberry has been examined by comparing infection and colonization on resistant Elliot and susceptible Jersey. Wharton and Schilder (2008) demonstrated significant differences in the time needed to cause infection in the resistant cultivar and Miles et al. (2011) supported these findings. In this current study, all blueberry FE stimulated secondary conidial production; however, the FE from susceptible Coville and Bluecrop stimulated significantly more appressorial production at $24 \mathrm{~h}$ postinoculation as compared with the more resistant cultivars Duke and Elliot. Equal levels of disease were recorded on Elliot fruit in the inoculation assay, indicating that $C$. fioriniae conidia in the presence of either FE over long infection periods (greater than $24 \mathrm{~h}$ ) are able to produce sufficient appressoria and secondary conidia for successful infections to occur. Cultivar susceptibility may be related to altered infection period duration in response to the FE of susceptible and resistant cultivars. If FE from susceptible varieties promote shorter infection periods, then there will be a greater number of overall infection periods, ultimately leading to higher levels of disease.

C. acutatum (sensu lato) has been shown to overwinter in the inflorescence buds of blueberry (DeMarsay 2005) as well as several other plant species, including apple (along with C. gloeosporioides) in Brazil (Bernardi et al. 1983), mulberry in Japan (Yoshida and Shirata 1999), and sour cherry and sweet cherry in Norway (Børve and Stensvand 2006). This overwintering reservoir is not unique to Colletotrichum spp. because other plant pathogens such as Xanthomonas arboricola pv. julandis also overwinter in flower buds, where there is a strong correlation of bacterial population size in dormant floral buds with disease incidence. (Lindow et al. 2014). This close proximity of primary inoculum with the developing floral tissues provides an opportunity for movement of chemical signals from flowers to the dormant pathogen, highlighting a possible evolutionary relationship.

C. fioriniae is also responsible for severe losses in V. macrocarpon and preliminary data (not presented) suggests that cranberry FE also stimulates important members of the cranberry fruit rot pathosystem (C. fioriniae, C. fructicola, and Coleophoma empetri) (Waller 2014). In agreement with this, all of the cranberry isolates evaluated in this study were dramatically affected by blueberry BC $\mathrm{FE}$, indicating similar disease cycle components in the cranberryColletotrichum fioriniae pathosystem. FE from K. latifolia L., L. mariana (L.) D. Don, R. maximum L., V. corymbosum L., and $V$. macrocarpon Ation stimulated both secondary conidiation and appressorial formation of $C$. fioriniae, suggesting some commonality among these FE. In addition to these findings, floral infections by $C$. acutatum (sensu lato) have been documented on numerous other host genera where flowers have been implicated in other aspects of the disease cycle beyond blossom necrosis (Adaskaveg and Hartin 1997; Jeffries et al. 1990; Maas 1984; Wharton and Diéguez-Uribeondo 2004; Zulfiqar et al. 1996).

This research raises several questions regarding the role of floral components in both secondary conidiation and appressorial formation. For example, ontogenic resistance, the process of changing susceptibility over time during development, may be influenced, in part, by the presence of flowers (Cooley et al. 1996; Ficke et al. 2002). In agreement with this, our results suggest that stimulatory floral compounds alter the infectivity of the pathogen by providing less stringent conditions for successful infection during bloom. This research identifies the importance of water-mobilized floral components during the initial stages of conidiation and appressorial formation of C. fioriniae and indicates the need for floral information in the development of effective integrated pest management strategies.

\section{ACKNOWLEDGMENTS}

We thank the student interns (notably, J. E. Lynch), graduate students (notably, J. D. Gager), and technicians who assisted in the procurement of the floral extract materials.

\section{LITERATURE CITED}

Adaskaveg, J. E., and Hartin, R. J. 1997. Characterization of Colletotrichum acutatum isolates causing anthracnose of almond and peach in California. Phytopathology 87:979-987.

Agostini, J. P., Gottwald, T. R., and Timmer, L. W. 1993. Temporal and spatial dynamics of postbloom fruit drop of citrus in Florida. Phytopathology 83: 485-490.

Bernardi, J., Feliciano, A., and Deassis, M. 1983. Occurrence of Glomerella cingulata (Colletotrichum gloeosporioides) in dormant floral buds and flowers of apple. Pesqui. Agropecu. Bras. 18:609-611.

Børve, J., and Stensvand, A. 2006. Colletotrichum acutatum overwinters on sweet cherry buds. Plant Dis. 90:1452-1456.

Boudreau, M. A., and Madden, L. V. 1995. Effect of strawberry density on dispersal of Colletotrichum acutatum by simulated rain. Phytopathology 85 : 934-941. 
Cardinali, A., and Nason, G. 2013. Costationarity of locally stationary time series using \{costat\}. J. Stat. Softw. 55:1-22.

Cooley, D. R., Wilcox, W. F., Kovach, J., and Schloemann, S. G. 1996. Integrated pest management programs for strawberries in the northeastern United States. Plant Dis. 80:228-237.

Damm, U., Cannon, P. F., Woudenberg, J. H. C., and Crous, P. W. 2012. The Colletotrichum acutatum species complex. Stud. Mycol. 73:37-113.

DeMarsay, A. 2005. Anthracnose Fruit Rot of Highbush Blueberry: Biology and Epidemiology. Rutgers University, New Brunswick, NJ.

Diéguez-Uribeondo, J., Forster, H., and Adaskaveg, J. E. 2004. Temperaturewetness relationships for Colletotrichum acutatum infections on almond blossoms and leaves. (Abstr.) Phytopathology 94:S25.

Diéguez-Uribeondo, J., Forster, H., and Adaskaveg, J. E. 2011. Effect of wetness duration and temperature on the development of anthracnose on selected almond tissues and comparison of cultivar susceptibility. Phytopathology 101:1013-1020.

Eastburn, D. M., and Gubler, W. D. 1990. Strawberry anthracnose-Detection and survival of Colletotrichum acutatum in soil. Plant Dis. 74:161-163.

Ficke, A., Gadoury, D. M., and Seem, R. C. 2002. Ontogenic resistance and plant disease management: A case study of grape powdery mildew. Phytopathology 92:671-675.

Freeman, S., Horowitz, S., and Sharon, A. 2001. Pathogenic and nonpathogenic lifestyles in Colletotrichum acutatum from strawberry and other plants. Phytopathology 91:986-992.

Freeman, S., and Shabi, E. 1996. Cross-infection of subtropical and temperate fruits by Colletotrichum species from various hosts. Physiol. Mol. Plant Pathol. 49:395-404

Gager, J. D. 2015. The Influence of Cranberry Floral Wax on Appressorium Formation in Colletotrichum fioriniae. Rutgers University, New Brunswick, NJ.

Guerber, J. C., Liu, B., Correll, J. C., and Johnston, P. R. 2003. Characterization of diversity in Colletotrichum acutatum sensu lato by sequence analysis of two gene introns, mtDNA and intron RFLPs, and mating compatibility. Mycologia 95:872-895.

Hartung, J. S., Burton, C. L., and Ramsdell, D. C. 1981. Epidemiological-studies of Blueberry Anthracnose disease caused by Colletotrichum gloeosporioides. Phytopathology 71:449-453.

Jeffries, P., Dodd, J. C., Jeger, M. J., and Plumbley, R. A. 1990. The biology and control of Colletotrichum species on tropical fruit crops. Plant Pathol. 39:343-366.

Jones, A. L., Ehret, G. R., Meyer, M. P., and Shane, W. W. 1996. Occurrence of bitter rot on apple in Michigan. Plant Dis. 80:1294-1297.

Kou, L. P., Gaskins, V., Luo, Y. G., and Jurick, W. M. 2014. First report of Colletotrichum fioriniae causing postharvest decay on 'Nittany' apple fruit in the United States. Plant Dis. 98:993.

Leandro, L. F. S., Gleason, M. L., Nutter, F. W., Wegulo, S. N., and Dixon, P. M. 2001. Germination and sporulation of Colletotrichum acutatum on symptomless strawberry leaves. Phytopathology 91:659-664.

Leandro, L. F. S., Gleason, M. L., Nutter, F. W., Wegulo, S. N., and Dixon, P. M. 2003. Strawberry plant extracts stimulate secondary conidiation by Colletotrichum acutatum on symptomless leaves. Phytopathology 93:1285-1291.

Lewis Ivey, M. L., Nava-Diaz, C., and Miller, S. A. 2004. Identification and management of Colletotrichum acutatum on immature bell peppers. Plant Dis. 88:1198-1204.

Lindow, S., Olson, W., and Buchner, R. 2014. Colonization of dormant walnut buds by Xanthomonas arboricola pv. juglandis is predictive of subsequent disease. Phytopathology 104:1163-1174.

Maas, J. L. 1984. Compendium of Strawberry Diseases. American Phytopathological Society, St. Paul, MN.

MacKenzie, S. J., Peres, N. A., and Timmer, L. W. 2010. Colonization of citrus leaves and secondary conidiation response to citrus flower extracts by nonpostbloom fruit drop strains of Colletotrichum acutatum. Trop. Plant Pathol. 35:333-342.

Madden, L. V., Yang, X. S., and Wilson, L. L. 1996. Effects of rain intensity on splash dispersal of Colletotrichum acutatum. Phytopathology 86: 864-874.

Marcelino, J., Giordano, R., Gouli, S., Gouli, V., Parker, B. L., Skinner, M., TeBeest, D., and Cesnik, R. 2008. Colletotrichum acutatum var. fioriniae (teleomorph: Glomerella acutata var. fioriniae var. nov.) infection of a scale insect. Mycologia 100:353-374.

Miles, T. D., Day, B., and Schilder, A. C. 2011. Identification of differentially expressed genes in a resistant versus a susceptible blueberry cultivar after infection by Colletotrichum acutatum. Mol. Plant Pathol. 12:463-477.

Miles, T. D., Gillett, J. M., Jarosz, A. M., and Schilder, A. M. C. 2013. The effect of environmental factors on infection of blueberry fruit by Colletotrichum acutatum. Plant Pathol. 62:1238-1247.
Milholland, R. D. 1995. Compendium of Blueberry and Cranberry Diseases. American Phytopathological Society, St. Paul, MN.

Miller, P. M. 1955. V-8 juice agar as a general purpose medium for fungi and bacteria. Phytopathology 45:461-462.

Moral, J., de Oliveira, R., and Trapero, A. 2009. Elucidation of the disease cycle of olive anthracnose caused by Colletotrichum acutatum. Phytopathology 99:548-556.

Oudemans, P. V., Caruso, F. L., and Stretch, A. W. 1998. Cranberry fruit rot in the northeast: A complex disease. Plant Dis. 82:1176-1184.

Oudemans, P. V., Polashock, J. J., Waller, T. J., and Constantelos, C. First report of anthracnose fruit rot of blueberry caused by Colletotrichum fioriniae in New Jersey. Plant Dis. In press.

Pennycook, S. R. 2017. Colletotrichum fioriniae comb. \& stat. nov., resolving a nomenclatural muddle. Mycotaxon 132:149-152(4).

Peres, N. A., Timmer, L. W., Adaskaveg, J. E., and Correll, J. C. 2005. Lifestyles of Colletotrichum acutatum. Plant Dis. 89:784-796.

Podila, G. K., Rogers, L. M., and Kolattukudy, P. E. 1993. Chemical signals from avocado surface wax trigger germination and appressorium formation in Colletotrichum gloeosporioides. Plant Physiol. 103:267-272.

Polashock, J. J., Caruso, F. L., Oudemans, P. V., McManus, P. S., and Crouch, J. A. 2009. The North American cranberry fruit rot fungal community: A systematic overview using morphological and phylogenetic affinities. Plant Pathol. 58:1116-1127.

Polashock, J. J., Ehlenfeldt, M. K., Stretch, A. W., and Kramer, M. 2005. Anthracnose fruit rot resistance in blueberry cultivars. Plant Dis. 89:33-38.

Prusky, D., Alkan, N., Mengiste, T., and Fluhr, R. 2013. Quiescent and necrotrophic lifestyle choice during postharvest disease development. Annu. Rev. Phytopathol. 51:155-176.

Pszczółkowska, A., and Okorski, A. 2016. First report of anthracnose disease caused by Colletotrichum fioriniae on blueberry in western Poland. Plant Dis. 100:2167.

Rodriguez-Salamanca, L. M. E., Byrne, J. M., Feng, C., and Correll, J. C. 2012. First report of Colletotrichum acutatum sensu lato causing leaf curling and petiole anthracnose on celery (Apium graveolens) in Michigan. Plant Dis. 96:1383.

Shivas, R. G., and Tan, Y. P. 2009. A taxonomic re-assessment of Colletotrichum acutatum, introducing $C$. fioriniae comb. et stat. nov. and $C$. simmondsii sp. nov. Fungal Divers. 39:111-122.

Smith, B. J., and Black, L. L. 1990. Morphological, cultural, and pathogenic variation among Colletotrichum species isolated from strawberry. Plant Dis. 74:69-76.

Sreenivasaprasad, S., and Talhinhas, P. 2005. Genotypic and phenotypic diversity in Colletotrichum acutatum, a cosmopolitan pathogen causing anthracnose on a wide range of hosts. Mol. Plant Pathol. 6:361-378.

Stretch, A. W. 1967. Occurrence of Glomerella cingulata on highbush blueberry. Plant Dis. Rep. 51:401-404.

USDA. 2016. Noncitrus Fruits and Nuts 2015 Summary (July 2016). R. Albert, ed. United States Department of Agriculture (USDA). Mann Library, Cornell University, Ithaca, NY

Verma, N., MacDonald, L., and Punja, Z. K. 2006. Inoculum prevalence, host infection and biological control of Colletotrichum acutatum: Causal agent of blueberry anthracnose in British Columbia. Plant Pathol. 55:442-450.

Verma, N., MacDonald, L., and Punja, Z. K. 2007. Environmental and host requirements for field infection of blueberry fruits by Colletotrichum acutatum in British Columbia. Plant Pathol. 56:107-113.

Waller, T. J. 2014. Response of blueberry and cranberry fruit rotting fungi to host plant floral extracts. Phytopathology 104:S3.

Wharton, P. S., Dickman, J. S., and Schilder, A. M. C. 2002. Timing of spore release by Colletotrichum acutatum in Michigan blueberry fields. Phytopathology 92:S86.

Wharton, P. S., and Diéguez-Uribeondo, J. 2004. The biology of Colletotrichum acutatum. An. Jardin Bot. Madrid 1979 61:3-22.

Wharton, P. S., and Schilder, A. C. 2008. Novel infection strategies of Colletotrichum acutatum on ripe blueberry fruit. Plant Pathol. 57:122-134.

Yang, X., Madden, L. V., Wilson, L. L., and Ellis, M. A. 1990. Effects of surface-topography and rain intensity on splash dispersal of Colletotrichum acutatum. Phytopathology 80:1115-1120.

Yoshida, S., and Shirata, A. 1999. The mulberry fungus, Colletotrichum acutatum, overwinters on mulberry tree. Ann. Phytopathol. Soc. Jpn. 65: 274-280.

Yoshida, S., Tsukiboshi, T., Shinohara, H., Koitabashi, M., and Tsushima, S. 2007. Occurrence and development of Colletotrichum acutatum on symptomless blueberry bushes. Plant Pathol. 56:871-877.

Zulfiqar, M., Brlansky, R. H., and Timmer, L. W. 1996. Infection of flower and vegetative tissues of citrus by Colletotrichum acutatum and C. gloeosporioides. Mycologia 88:121-128. 